Mini Review

\title{
Removal of Chromium Using Electrochemical Approaches: A Review
}

\author{
Yuxiang Zhao, Dejun Kang ${ }^{*}$, Zhong Chen, Jiajun Zhan, Xiaoqi Wu
}

College of Civil Engineering, Fuzhou University, Fuzhou City, Fujian Province, 350116, P.R. China E-mail: yuxiangzhao168@126.com

doi: $10.20964 / 2018.02 .46$

Received: 30 September 2017 / Accepted: 15 November 2017 / Published: 28 December 2017

In the manufacturing industry, chromium is often discharged with the effluent, which releases significant contamination to the environment. To remove chromium from wastewater, many different treatment techniques have been developed. The present work reports the treatment of chromium pollution using electrochemical-based remediation strategies, including electrodeionization, electrodialysis, electrochemical reduction, and electrocoagulation. This work also presents the principles and mechanisms of these strategies, along with research trends into the electrochemical removal of chromium.

Keywords: Chromium removal; Electrochemical; Electrodeionization; Electrocoagulation; Electrochemical reduction; Electrodialysis

\section{FULL TEXT}

(C) 2018 The Authors. Published by ESG (www.electrochemsci.org). This article is an open access article distributed under the terms and conditions of the Creative Commons Attribution license (http://creativecommons.org/licenses/by/4.0/). 